\title{
Elucidation of some Bax conformational changes through crystallization of an antibody-peptide complex
}

\author{
FW Peyerl ${ }^{1}$, S Dai ${ }^{1}$, GA Murphy ${ }^{1}$, F Crawford ${ }^{1}$, J White ${ }^{1}$, P Marrack ${ }^{1,2,3}$ and JW Kappler ${ }^{*, 1,2,4}$
}

The Bcl-2 family member Bax plays a critical role in apoptosis. In healthy resting cells, Bax resides in the cytoplasm and loosely attached to the mitochondrial membrane. Apoptotic stimuli induce Bax activation, which is characterized by translocation and multimerization on the mitochondrial membrane surface resulting in exposure of an amino terminal epitope recognized by the monoclonal antibody 6A7. To understand the structural changes that occur during Bax activation, we determined the crystal structure of a Bax peptide bound to the $6 A 7 \mathrm{Fab}$ fragment to a resolution of $2.3 \AA$. The structure reveals the conformation of the 6A7 peptide epitope on Bax in the activated form and elucidates the extensive structural changes that Bax must undergo during the conversion from its native to its activated conformation.

Cell Death and Differentiation (2007) 14, 447-452. doi:10.1038/sj.cdd.4402025; published online 1 September 2006

The Bcl-2 family of anti- and proapoptotic proteins plays an essential role in regulating apoptosis. ${ }^{1-3}$ All the members of this family share at least one conserved $\mathrm{Bcl}-2$ homology $(\mathrm{BH})$ domain. ${ }^{4}$ The antiapoptotic proteins (Bcl-2, Bcl-xl, Mcl-1, and A1) have all four $\mathrm{BH}$ domains. The proapoptotic proteins can be further subdivided on the basis of the number of $\mathrm{BH}$ domains they possess. Members of the 'BH3-only' subfamily (Bad, Bid, Bik, Bim, Noxa, and Puma) contain only the BH3 minimal death domain. In contrast, the more conserved multidomain members (Bak, Bax, and Bok) contain the BH1, $\mathrm{BH} 2$, and $\mathrm{BH} 3$ domains. It is the intricate interaction among members of the Bcl-2 family of proteins that represents a critical checkpoint in apoptosis.

One of the hallmarks of apoptosis is the loss of mitochondrial membrane potential followed by the release of cytochrome $c$ and other cytotoxic factors. ${ }^{5,6}$ Studies in knockout mice have demonstrated a requirement for either Bak or Bax in the initiation of mitochondrial dysfunction and in the death of T cells. ${ }^{7}$ In healthy cells, Bax exists as a monomer either in the cytosol or loosely attached to the outer mitochondrial membrane, ${ }^{8}$ whereas during apoptosis it is thought to function mainly as an oligomer at the mitochondrial membrane surface., ${ }^{4,9}$ In fact, the cytosolic and loosely attached Bax (native) can be distinguished from the Bax inserted into the mitochondria membrane (activated) by a conformational change in the amino-terminus that alters its recognition by two different monoclonal antibodies (Mabs), 5B7 and $6 \mathrm{~A} 7 .^{8,10-12}$ Specifically, the $5 \mathrm{~B} 7$ antibody recognizes an epitope comprised of amino acids 7-14 of Bax which is accessible on both the native and activated forms of Bax. In contrast, the $6 \mathrm{~A} 7$ antibody recognizes an epitope comprised of amino acids $13-19$ of Bax, which is only accessible on the activated form (Figure 1a). Thus, the exposure of the 6A7 antibody epitope marks an important transition and conformational change in the Bax-mediated apoptosis pathway. However, to date there is no crystallographic information regarding the structural rearrangements that occur to Bax upon activation.

Because of the significance associated with Bax exposure of the 6A7 epitope, we sought to determine the extent of the structural changes that Bax undergoes during apoptosis. Structural determination of the proapoptotic Bcl-2 family members has been difficult for several reasons. The propensity of these proteins to induce death across multiple kingdoms limits their production in typical protein expression systems. ${ }^{13}$ In addition, in vitro detergent-mediated activation of recombinant Bax protein results in the spontaneous aggregation and precipitation of the protein, a state which cannot easily be analyzed structurally. ${ }^{11}$ This is further illustrated by the fact that the majority of the crystal structures involving these proteins are complexes of either Bcl-2 or Bcl-xl and a proapoptotic peptide fragment rather than the intact proapoptotic protein. ${ }^{13-17}$ To overcome these technical difficulties, we have solved the crystal structure of a $6 \mathrm{~A} 7$ Fab fragment in complex with a peptide fragment of Bax. The structure reveals the conformation of the Bax peptide epitope in the activated form. In addition, the structure demonstrates why the $6 \mathrm{~A} 7$ antibody cannot bind to the native Bax. Finally, the structure suggests that Bax undergoes considerable structural changes when it converts from its native to its activated conformation.

\footnotetext{
${ }_{1}^{1}$ Howard Hughes Medical Institute, Integrated Department of Immunology, Zuckerman Family/Canyon Ranch Crystallography Laboratory, National Jewish Medical and Research Center, Denver, CO, USA; ${ }^{2}$ Integrated Department of Immunology, University of Colorado Health Science Center, Denver, CO, USA; ${ }^{3}$ Department of Biochemistry and Molecular Genetics, University of Colorado Health Science Center, Denver, CO, USA and ${ }^{4}$ Department of Pharmacology and Program in Biomolecular Structure, University of Colorado Health Science Center, Denver, CO, USA

*Corresponding author: JW Kappler, Howard Hughes Medical Institute, National Jewish Medical and Research Center, 1400 Jackson Street, Denver, CO 80206 , USA. Tel: + 303398 1322; Fax: + 303398 1396; E-mail: kapplerj@njc.org

Keywords: Bax; 6A7; structural changes; crystal structure; antibody-peptide complex

Abbreviations: $\mathrm{BH}, \mathrm{BCl}-2$ homology; $\mathrm{CDR}$, complementarity determining region; PEG, polyethylene glycol; $\mathrm{CNS}$, Crystallography \& NMR System

Received 29.5.06; revised 13.7.06; accepted 14.7.06; Edited by DR Green; published online 01.9.06
} 
a

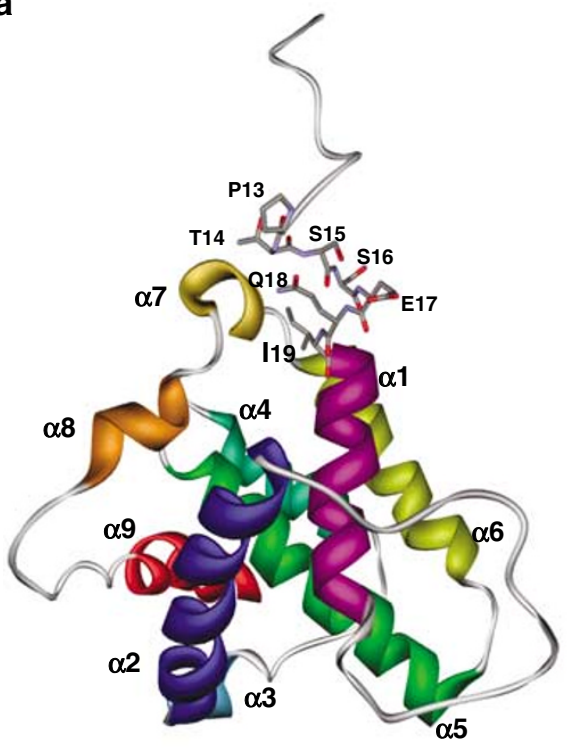

b

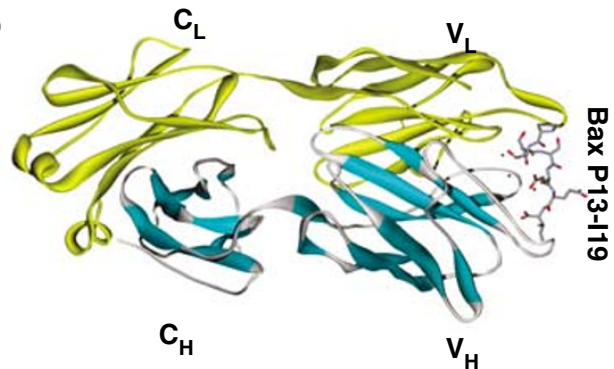

C

S15

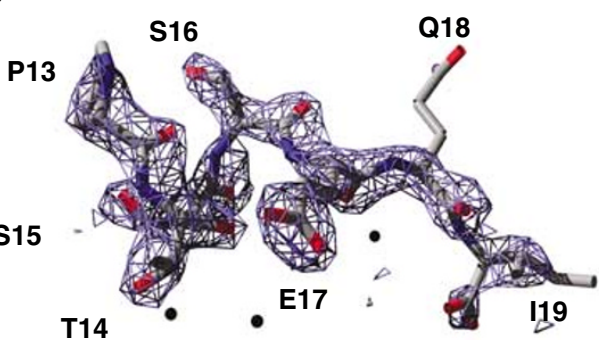

Figure 1 Structure of the full-length Bax protein. (a) A ribbon representation of the first of 20 lowest energy NMR structures of human Bax (PDB 1 F16). ${ }^{18}$ Helices are distinguished by different colors. Residues S16-A35, $\alpha 1$; A54-D71, $\alpha 2$; M74-A81, $\alpha 3$; R89-M99, $\alpha 4$; G108-C126, $\alpha 5$; P130-E146, $\alpha 6$; L149-D154, $\alpha 7$; W158-Y164, $\alpha 8$; and W170-W188, $\alpha 9$. The fragment of Bax (P13-119) that binds the 6A7 Fab is shown in wire frame; gray, carbon; red, oxygen; blue, nitrogen. (b) Structure of a peptide fragment of Bax bound to the $6 \mathrm{~A} 7 \mathrm{Fab}$. Ribbon diagram of the $6 \mathrm{~A} 7 \mathrm{Fab}$ bound to a peptide fragment of Bax (P13 - I19). Cyan, 6A7 Fab heavy chain; yellow, $6 \mathrm{A7}$ Fab light chain; wire frame, Bax peptide. (c) Peptide omit electron density map (Fo-Fc, 2.25 $\sigma$ ) surrounding the Bax peptide. The figure was made using Swiss PDBViewer

\section{Results}

Structure determination of a 6A7 Fab-Bax peptide complex. When Bax is in its soluble monomeric conformation (called here 'native'), the stretch of amino acids recognized by the 6A7 antibody, Bax 13-19 (PTSSEQI), is intimately associated with the globular core of Bax and is not recognized by $6 \mathrm{~A} 7 .^{11,18}$ Coincident with activation and translocation to the mitochondrial membrane, Bax undergoes a conformation change that exposes the 6A7 epitope and induces oligomerization. ${ }^{11,19}$ This conformational change can be mimicked in vitro by the addition of nonionic detergents such as NP-40 and Triton $\mathrm{X}-100 .{ }^{11}$ Because detergent-activated Bax spontaneously oligomerizes and aggregates in vitro, ${ }^{11,20}$ it is technically difficult to crystallize Bax in this conformation. Therefore, to determine the structural changes, which occur to Bax following activation, the crystal structure of a $6 \mathrm{~A} 7 \mathrm{Fab}-\mathrm{Bax}$ peptide complex was determined at $2.3 \AA$ resolution.

Concentrated 6A7 Fab-peptide complexes were crystallized by hanging-drop vapor diffusion. Crystals grew within 1-2 weeks and were harvested and frozen in liquid nitrogen for X-ray data collection. The data were indexed into space group $\mathrm{P} 2{ }_{1} 2{ }_{1} 2$ with four $6 \mathrm{~A} 7$ Fab-peptide complexes per asymmetric unit $(49.06 \%$ solvent content) (Table 1$)$. The structure was determined by molecular replacement using an unliganded germline mouse Fab Protein Data Bank (PDB identifier $1 \mathrm{Q} 9 \mathrm{~V}$ ) as the initial search model. ${ }^{21}$

Because the four averaged molecules in the asymmetric unit were similar, only molecule 1 will be described here (Figure 1b). The 6A7 Fab-Bax peptide complex had good stereochemistry with only A151 from the light chain in the
Table 1 Data collection and refinement statistics

\begin{tabular}{|c|c|}
\hline Data collection & 6A7 Fab and Bax P13-I19 \\
\hline $\begin{array}{l}\text { Space group } \\
\text { Unit cell dimensions }(\AA) \\
\text { Unit cell angles }\left({ }^{\circ}\right) \\
\text { No. of molecule in AU } \\
\text { Resolution limits }(\AA) \\
\text { Unique reflections } \\
\text { Completeness }(\%) \\
\text { Average redundancy } \\
\text { Average } 1 / \sigma \\
\text { Rmerge }(\%)^{\mathrm{b}}\end{array}$ & $\begin{array}{c}\mathrm{P} 2_{1} 2_{1} 2 \\
a=166.528, b=183.897 \\
c=67.081 \\
\alpha=90, \beta=90, \gamma=90 \\
4 \\
49.58-2.2(2.28-2.20)^{\mathrm{a}} \\
106760 \\
99.9(100.0) \\
5.71(5.68) \\
7.3(1.6) \\
10.6(63.0)\end{array}$ \\
\hline $\begin{array}{l}\text { Refinement } \\
\text { Resolution }(\AA) \\
\text { Rejection criteria } \\
\text { Total reflections } \\
\text { Reflections used for } R_{\text {free }} \\
R_{\text {working }}(\%) \\
R_{\text {free }}(\%) \\
\text { Average B factors }\left(\AA^{2}\right)\end{array}$ & $\begin{array}{c}20-2.3(2.38-2.30) \\
F \leqslant 0 \\
91909(9033) \\
4606(458) \\
23.32(30.54) \\
27.41(34.42) \\
42.98\end{array}$ \\
\hline $\begin{array}{l}\text { Ramachandran data } \\
\text { Number of residues in (\%): } \\
\text { Favored regions } \\
\text { Allowed regions } \\
\text { Generously allowed regions } \\
\text { Disallowed regions }\end{array}$ & $\begin{array}{c}1255(88.6) \\
153(10.8) \\
4(0.3) \\
4(0.3)\end{array}$ \\
\hline $\begin{array}{l}R m s d \\
\text { Bonds }(\AA) \\
\text { Angles }\left(^{\circ}\right) \\
\text { B factor main chain }\left(\AA^{2}\right) \\
\text { B factor side chain }\left(\AA^{2}\right) \\
\text { Cross-validated coord. error }(\AA)\end{array}$ & $\begin{array}{l}0.0061 \\
1.340 \\
4.867 \\
7.745 \\
0.39\end{array}$ \\
\hline
\end{tabular}

${ }^{\mathrm{a} A l l}$ data (outer shell). $\quad{ }^{\mathrm{b}} \mathrm{Rmerge}=\Sigma(|I-\langle I\rangle|) / \Sigma(\Lambda) . \quad{ }^{\mathrm{c}}$ Rworking/free$\Sigma \|\left|F_{\mathrm{o}}\right|-\left|F_{\mathrm{c}}\right| / \Sigma\left|F_{\mathrm{o}}\right|$. 
disallowed region (Table 1), which is a highly conserved $\gamma$ turn in most antibody structures. ${ }^{22}$ The electron density omit map clearly defined the orientation and conformation of the Bax peptide in the $6 \mathrm{~A} 7$ binding site (Figure 1c). The only peptide side chain residue with poorly defined electron density was solvent-exposed Q18.

Native and Fab bound conformations of Bax P13-I19. The Bax 6A7 epitope is located near the N-terminus of the Bax protein in an orientation, which is inaccessible to the $6 \mathrm{~A} 7$ antibody (Figure 1a). In this native conformation, P13, $\mathrm{T} 14$, and $\mathrm{S} 15$ are in an extended conformation whereas S16, E17, Q18, and 119 make the first canonical $\alpha$-helical turn of Bax $\alpha 1$ (Figure 2a). In addition, multiple intraepitope hydrogen bonds are observed between the amino-acid side chains and backbone atoms of this portion of Bax as well as characteristic $\alpha$-helical hydrogen bonds between the main chain carbonyl oxygen and amino groups (Figure 2a). Finally, the longest distance between the nitrogen of $\mathrm{P} 13$ and the carbonyl oxygen of $\mathrm{I} 19$ is only $12.84 \AA$. Although the fragment of Bax shown here represents only one of 20 solution structures for the native conformation of $\mathrm{Bax}^{18}$ the average distance between the nitrogen of P13 and the carbonyl oxygen of $\mathrm{I} 19$ is $13.61 \AA$. Thus, the overall conformation of the $6 \mathrm{~A} 7$ epitope in the native conformation of Bax is relatively $\alpha$-helical and compact.

Interestingly, the peptide from the same region of Bax assumed an entirely different conformation when bound to the 6A7 Fab (Figure 2b). Although P13, T14, and S15 were still in an extended conformation, S16 - I19 were also bound to the Fab in a fully extended conformation. Moreover, the only observed intraepitope hydrogen bonds occurred between $\mathrm{P} 13, \mathrm{~T} 14$, and S15. The binding of the Bax peptide to the $6 \mathrm{~A} 7$ Fab was stabilized by an extensive network of hydrogen bonds between all but two residues of the peptide, multiple water molecules, and residues from both the 6A7 heavy and light chains. The only two peptide residues that were not directly interacting with the Fab were S16 and Q18, which are completely solvent-exposed. The extended conformation of the Bax peptide measured $14.5 \AA$ from $\mathrm{P} 13$ to 119 , a $6 \%$ increase in length compared to the native structure.

In addition to the conformational changes that were observed between the native and 6A7-bound Bax epitope, the orientation of the Bax peptide in the Fab binding site suggests that the amino terminus of Bax cannot simultaneously be bound by the Fab and also retain its binding to the
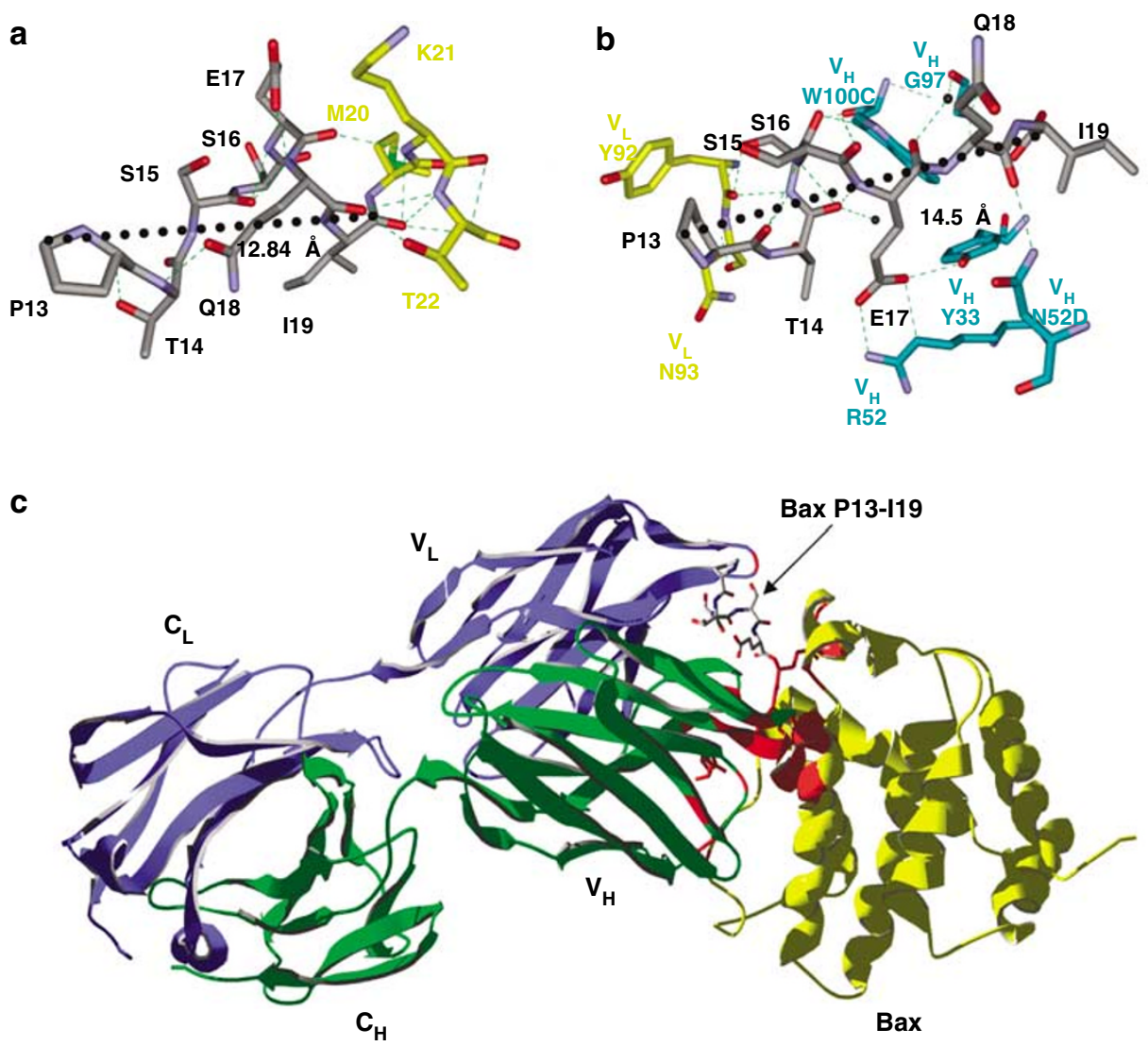

Figure 2 Details of the P13-119 fragment of Bax. Shown are the wire frame representations of the P13-119 fragment of Bax in the native (a) and Fab bound (b) conformations. (a) Gray, Bax P13-I19 carbon; yellow, Bax M20-T22 carbon; red, oxygen; blue, nitrogen. (b) Gray, Bax peptide carbon; yellow, Fab light chain carbon; cyan, Fab heavy chain carbon; red, oxygen; blue, nitrogen. Hydrogen bonds are shown as green dashed lines. Black dotted line indicates the longest distance from P13 to I19 in both conformations. (c) Steric hindrance prevents binding between 6A7 Fab and native Bax. A ribbon representation of Bax bound to the 6A7 Fab. Yellow, Bax (PDB 1F16) ${ }^{18}$ truncated at M20; blue, Fab light chain; green, Fab heavy chain. Bax P13-I19 is depicted in wire frame with gray, carbon; red, oxygen; blue, nitrogen. Red residues indicate amino acid side chains that are clashing in the complex 
Bax protein. In fact, the way in which the $6 \mathrm{~A} 7 \mathrm{Fab}$ binds to the Bax peptide epitope implies that a drastic structural change must occur to Bax to permit binding to the $6 \mathrm{~A} 7$ antibody. Specifically, in the native Bax, the $\alpha 1$ helix tightly interacts with the hydrophobic interior of the protein through multiple van der Waals contacts with $\alpha 2, \alpha 5, \alpha 6$, and $\alpha 7$ helices. The extended conformation of the Bax epitope when bound to the $6 \mathrm{~A} 7$ precludes some of these interactions with the protein interior. For example, I19 is buried within the hydrophobic core in the native Bax structure (Figure 1a) and is flanked by the CDR2 and CDR3 loops when bound to the 6A7 Fab (Figure 1b). The intimate involvement of $\mathrm{I} 19$ in both the native and 6A7-bound conformations of Bax immediately implies the need for additional structural changes to Bax to facilitate $6 \mathrm{~A} 7$ antibody binding.

Predicted Fab binding to full-length Bax. The two Baxspecific Mabs 5B7 and 6A7 possess remarkably different binding characteristics despite having overlapping epitopes. $5 \mathrm{~B} 7$ has been shown to recognize both the native and the activated conformations of Bax whereas $6 \mathrm{~A} 7$ recognizes only the latter form. ${ }^{10,11}$ To assess additional structural changes that Bax must undergo in order to allow binding to the $6 \mathrm{~A} 7$ antibody, we modeled the 6A7 Fab bound to the previously published structure of native Bax. ${ }^{18}$ To create the $6 \mathrm{~A} 7 \mathrm{Fab}-$ Bax complex, we first removed the amino terminal 19 residues of native $\operatorname{Bax}(\operatorname{Bax} \Delta 19)$. The $M 20$ of $\operatorname{Bax} \Delta 19$ was then covalently linked to I19 of the 6A7 Fab-Bax peptide complex. Rotation of the complex about the Bax I19- M20 peptide bond revealed numerous clashes between the $6 \mathrm{~A} 7$ Fab and Bax. In fact, in the best orientation, no fewer than 27 residues and backbone atoms of the Fab-Bax complex clashed (Figure 2c). Specifically, in this orientation one residue of the $6 \mathrm{~A} 7$ light chain (K30), 10 residues of the $6 \mathrm{~A} 7$ heavy chain (F27, D31, N52A - N52D, Y53, R69, N96, and S98), two residues of the Bax P13 - I19 peptide (Q18 and I19), and 14 residues of the rest of the Bax protein (Bax $\Delta 19$ ) (M20, K21, G23, A24, L47, L141, D142, L144 - E146, L149, I152, G156, and G157) were found to clash. In addition, K21 of Bax was found to clash with the $\mathrm{N}$-linked carbohydrate of N96 on the CDR3 loop of the 6A7 heavy chain. Thus, when $\mathrm{Bax}$ is in its native conformation a significant degree of steric hindrance precludes binding of the $6 \mathrm{~A} 7 \mathrm{Fab}$ to the Bax protein.

To estimate the extent of additional rearrangements to Bax that are required to facilitate binding of the $6 \mathrm{~A} 7 \mathrm{Fab}$, we separated the Fab-Bax peptide complex from the Bax $\Delta 19$ protein (Figure $3 a$ ). To eliminate all of the observed steric hindrance, the 6A7 Fab-Bax peptide complex had to be moved a minimum of $9.5 \AA$ away from the Bax $\Delta 19$ protein (Figure $3 b$ ). Even at this position, several residues of the $6 \mathrm{~A} 7$ Fab heavy chain were still close enough to the Bax $\Delta 19$ protein to form an extensive hydrogen-bonding network (data not shown). Finally, these data support the notion that Bax undergoes a significant structural change when converting from the native to the activated conformation.

\section{Discussion}

This study details one of the structural changes that is required of Bax when it converts from its native conformation to its activated conformation during apoptosis. Because
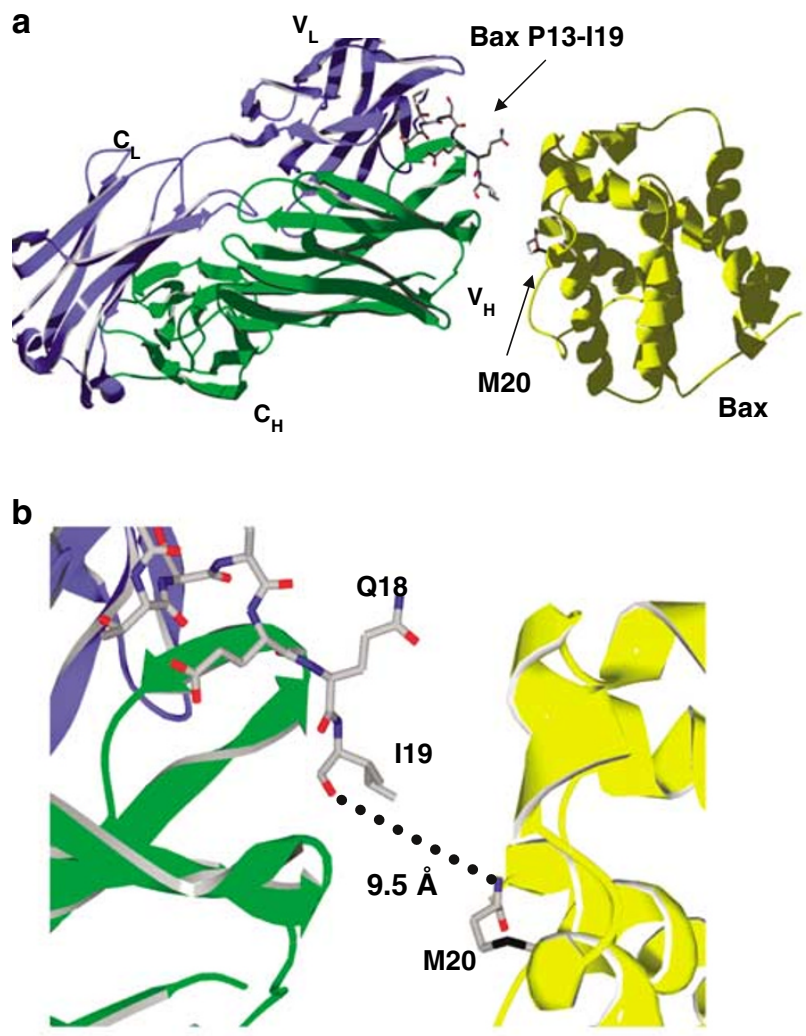

Figure 3 Minimal separation of the Bax and 6A7 Fab complex required to eliminate amino acid side chain clashes. (a) A ribbon representation of Bax and the 6A7 Fab bound to Bax P13-I19. (b) Close-up view of the separated Bax and 6A7 Fab complex. Yellow, Bax (PDB 1F16) ${ }^{18}$ truncated at M20; blue, Fab light chain; green, Fab heavy chain. Bax P13-M20 is depicted in wire frame with gray, carbon; red, oxygen; blue, nitrogen. Black dotted line indicates the distance between Bax I19 and M20 when no amino acid side chains are clashing

full-length activated Bax protein spontaneously aggregates, we crystallized a small peptide fragment of Bax with the conformation-specific 6A7 antibody. Nevertheless, the $2.3 \AA$ resolution structure details the significant changes that occur to the $\mathrm{N}$-terminus of the Bax protein following activation. Specifically, it shows the shift of the Bax 6A7 peptide epitope from a compact $\alpha$-helical conformation to an extended conformation. Moreover, we have shown that the $6 \mathrm{~A} 7$ recognition requires far more than just lengthening of this epitope. Computer modeling clearly demonstrated that the epitope must be moved at least $9.5 \AA$ away from the rest of the protein to eliminate steric hindrances between the 6A7 Fab and the native Bax protein.

To accommodate the required $9.5 \AA$ displacement of the Bax 6A7 epitope, at least two scenarios can be envisioned. The first scenario requires additional unwinding of the $\alpha 1$ helix of Bax. We know that each amino acid of an $\alpha$-helix increases the length of the helix by $1.5 \AA$, whereas the maximum distance between the carbonyl oxygen of two sequential amino acids of a polypeptide chain in a fully extended conformation is approximately $3.5 \AA$. Therefore, a gain of $9.5 \AA$ would require the additional unwinding of one to two turns of $\operatorname{Bax} \alpha 1$. Importantly, of the four residues comprising the 1.33 helical turns following 
the 6A7 epitope, only M20 and T22 are engaged in van der Waals contacts with internal Bax residues. Furthermore, the fourth residue is G23, which could provide a pivot point for unwinding and dissociation of the $\alpha 1$ helix from the Bax protein, given its flexibility and lack of helical propensity. Thus, further unwinding of the $\alpha 1$ helix represents one plausible model of the conformational changes Bax undergoes during apoptosis.

The second scenario involves movement of the entire $\alpha 1$ helix away from the hydrophobic core about the loop that connects $\alpha 1$ and $\alpha 2$. Although a conformational change of this magnitude would require significant rearrangement of other parts of the protein, there is evidence to suggest that such a change occurs. First, the $\operatorname{Bax} \alpha 1$ helix has been shown to interact directly with the BH3-only family member Bid. Moreover, this interaction is inhibited with the addition of soluble peptide spanning the entire $\alpha 1$ helix suggesting that the interaction requires the complete $\alpha 1$ helix. ${ }^{12,23,24}$ Second, the $\alpha 1$ helix of Bax has been shown to control its mitochondrial addressing, a process that probably requires displacement of $\alpha 1{ }^{25,26}$ Finally, and most importantly, three-dimensional NMR analysis of the detergent-induced conformation changes of Bax, that are thought to mimic Bax activation, shows that the $\alpha 1$ helix and the $\alpha 1 / \alpha 2$ loop are flexible and solvent-exposed in Bax oligomers. ${ }^{18}$

The NMR solution structure of native Bax shows substantial flexibility of Bax at the $\mathrm{N}$-terminus with the length of the $6 \mathrm{~A} 7$ epitope ranging between 10.68 and $15.98 \AA .{ }^{18}$ In addition, it is known that Bax exposure of the $6 \mathrm{~A} 7$ epitope is a reversible event that precedes oligomerization. ${ }^{27-29}$ Taken together, these events favor a model where seemingly minimal changes, such as the additional unwinding of $\alpha 1$, to the overall structure of Bax would permit the transient exposure of the $6 \mathrm{~A} 7$ epitope in the absence of complete Bax activation and oligomerization. Although it is likely that a complete unpacking and/or unwinding of the $\alpha 1$ helix from the hydrophobic core would disrupt additional regions of the Bax protein, this may in fact represent the initiating event for the subsequent downstream effects of Bax.

Although it is not known for certain what regions of Bax are required for oligomerization, biochemical experiments and crystallographic modeling suggests that cysteines in $\alpha 2$ and $\alpha 5$ are involved in Bax homodimerization. ${ }^{20}$ Moreover, whereas it is well established that $\alpha 9$ contains a putative transmembrane domain, it has also been suggested that $\alpha 5$ and $\alpha 6$ contribute to the formation of a multispanning monomer that then oligomerizes to form a pore in the mitochondrial membrane. ${ }^{30}$ In both of these cases, destabilization of Bax by displacement of the $\alpha 1$ helix from the hydrophobic core may drive the formation of the more stable multispanning complexes that are found tightly bound to the mitochondrial membrane. ${ }^{31-33}$ Although we cannot definitively conclude from this crystal structure which, if either, of the two scenarios is occurring with the activation of Bax, it is clear that additional alterations are required to permit $6 \mathrm{~A} 7$ antibody binding to Bax. Moreover, these data represent the first crystallographic indication of the nature of the conformational changes, which occur when the proapoptotic BH3-family member Bax converts from its innocuous to its activated form.

\section{Materials and Methods}

Expression and purification. The $6 \mathrm{~A} 7$ anti-Bax N-terminal Mab was prepared from supernatants of the $6 \mathrm{~A} 7$ cell line, generously provided by $\mathrm{Dr}$. Richard Youle (National Institutes of Health, Bethesda, MD, USA). ${ }^{11}$ The 6 A7 Mab was originally produced by fusing NS-1 myeloma cells with immunoreactive mouse splenocytes. Because the NS-1 cell line expresses an endogenous lambda light chain and the 6A7 Mab utilizes a kappa light chain, Protein $L$ (Pierce) was used to purify $6 \mathrm{~A} 7 \mathrm{Mab}$ from nonspecific contaminating antibodies found in the $6 \mathrm{~A} 7$ hybridoma supernatant. The $6 \mathrm{~A} 7$ antibody was eluted from the Protein $\mathrm{L}$ column with $0.1 \mathrm{M}$ glycine- $\mathrm{HCl}, \mathrm{pH} \mathrm{2.7}$, and immediately neutralized with $1 \mathrm{M} \mathrm{Tris,} \mathrm{pH} 9.0$. The fractions containing 6A7 Mab were combined, concentrated and buffer exchanged into PBS using an Amicon Ultra filter with $30 \mathrm{KDa}$ molecular weight cutoff (Millipore). Fab fragments from the purified antibody were prepared by overnight digestion at $37^{\circ} \mathrm{C}$ with papain (Sigma) using 5 units $/ 2.5 \mathrm{mg}$ of $6 \mathrm{~A} 7$ antibody in the presence of $10 \mathrm{mM} \beta$-mercaptoethanol. The reaction was stopped by buffer exchanging into PBS using an Amicon Ultra filter with $10 \mathrm{KDa}$ molecular weight cutoff (Millipore). Fab fragments were then poured over Protein $L$ (Pierce), eluted with $0.1 \mathrm{M}$ glycine- $\mathrm{HCl}, \mathrm{pH} 2.7$, and immediately neutralized upon collection with $1 \mathrm{M}$ Tris, pH 9.0, and buffer exchanged into $20 \mathrm{mM}$ Tris-HCl, pH 8.0. Fragments were further purified by anion-exchange using a Mono Q HR $5 / 5$ column on an AKTA FPLC (Pharmacia) using a linear gradient from 0 to $1.0 \mathrm{M} \mathrm{NaCl}$ in $10 \mathrm{mM}$ Tris$\mathrm{HCl}$, pH 8.0. Fractions containing $6 \mathrm{~A} 7 \mathrm{Fab}$ fragments were combined, concentrated and buffer exchanged to $10 \mathrm{mg} / \mathrm{ml}$ in PBS.

Crystallization and data collection. A synthetic peptide corresponding to the defined 6A7 epitope from Bax (AA 13-19, PTSSEQI) ${ }^{11}$ was premixed with purified $6 A 7$ Fab fragments at a $10: 1$ molar ratio and incubated at $18^{\circ} \mathrm{C}$ for $1 \mathrm{~h}$. The 6A7 Fab-peptide complex was purified and concentrated to $10 \mathrm{mg} / \mathrm{ml}$ using an Amicon Ultra filter with $10 \mathrm{KDa}$ molecular weight cutoff. The complex was crystallized by hanging-drop vapor diffusion at $18^{\circ} \mathrm{C}$. Drops were assembled with $2 \mu \mathrm{l}$ 6A7 Fab-peptide complex mixed with $2 \mu$ of well solution containing $20 \%$ polyethylene glycol (PEG) 8000, 0.1 M Tris- $\mathrm{HCl}, \mathrm{pH} 7.35,0.4 \mathrm{M}$ lithium sulfate. Crystals typically appeared within 1-2 weeks. Single crystals were harvested into $28 \% \mathrm{PEG} 8000,0.1 \mathrm{M}$ Tris- $\mathrm{HCl}, \mathrm{pH} 7.35,0.4 \mathrm{M}$ lithium sulfate and frozen in liquid nitrogen. These crystals typically diffracted to $3.5 \AA$ at home source. A complete data set for a single $6 \mathrm{~A} 7 \mathrm{Fab}$-peptide complex were collected at $100 \mathrm{KDa}$ at the Molecular Biology Consortium beamline 4.2.2, at the Advanced Light Source (Berkeley, CA, USA). 6A7 Fab-peptide complex crystals diffracted to 2.3- $\AA$ resolution and belonged to space group $\mathrm{P} 2{ }_{1}{ }_{2}{ }_{1}$, with $a=166.528, b=183.897$, $c=67.081$ with four Fab molecules per asymmetric unit. Synchrotron data were indexed and scaled using the program $d^{*}$ TREK (Rigaku Inc.). ${ }^{34}$

Structure determination. The structure of the 6A7 Fab-peptide complex was solved by molecular replacement using the program AMoRe. ${ }^{35,36}$ The search model was an unliganded mouse germline Fab ((PDB) identifier 1Q9V) with the loops connecting the constant and variable regions removed. ${ }^{21}$ The initial model was improved with rigid body refinement using the program Crystallography \& NMR System (CNS). ${ }^{37}$ Multiple rounds of refinement with CNS and model building with 0 were used to improve the model when the peptide was added. ${ }^{38}$ The final model of the 6A7 Fab-Bax peptide complex had 2183 amino acids. In the later stages of refinement, a single $\mathrm{N}$-acetyl glucosamine was added to asparagines (N96) based on positive electron density in Fo-Fc maps. In addition, 436 water molecules were added. Refinement and final model statistics are listed in Table 1. For figures, average structures were calculated from the four molecules in the asymmetric unit using noncrystallographic symmetry and the program CNS. Coordinates have been submitted to the PDB (available at http://www.rcsb.org/pdb/ under accession number 2G5B).

Acknowledgements. This work was supported by USPHS Grants Al-18785, Al-17136, and Al-22295. We thank Dr. Richard Youle for the 6A7 hybridoma cell line, without which this project would not have been possible. We thank Jay Nix and Darren Sherrell at the Molecular Biology Consortium beamline 4.2.2 at ALS for assistance with data collection.

1. Cory S, Adams JM. The Bcl2 family: regulators of the cellular life-or-death switch. Nat Rev Cancer 2002; 2: 647-656.

2. Hildeman DA, Zhu Y, Mitchell TC, Kappler J, Marrack P. Molecular mechanisms of activated T cell death in vivo. Curr Opin Immunol 2002; 14: 354-359. 
3. Strasser A, Bouillet $P$. The control of apoptosis in lymphocyte selection. Immunol Rev 2003; 193: 82-92.

4. Gross A, McDonnell JM, Korsmeyer SJ. BCL-2 family members and the mitochondria in apoptosis. Genes Dev 1999; 13: 1899-1911.

5. Marsden VS, Strasser A. Control of apoptosis in the immune system: Bcl-2, BH3-only proteins and more. Annu Rev Immunol 2003; 21: 71-105.

6. Rudin CM, Thompson CB. Apoptosis and disease: regulation and clinical relevance of programmed cell death. Annu Rev Med 1997; 48: 267-281.

7. Wei MC, Zong WX, Cheng EH, Lindsten T, Panoutsakopoulou V, Ross AJ et al. Proapoptotic BAX and BAK: a requisite gateway to mitochondrial dysfunction and death. Science 2001; 292: 727-730.

8. Sharpe JC, Arnoult D, Youle RJ. Control of mitochondrial permeability by Bcl-2 family members. Biochim Biophys Acta 2004; 1644: 107-113.

9. Martinou JC, Green DR. Breaking the mitochondrial barrier. Nat Rev Mol Cell Biol 2001; 2 63-67.

10. Nechushtan A, Smith CL, Hsu YT, Youle RJ. Conformation of the Bax C-terminus regulates subcellular location and cell death. EMBO J 1999; 18: 2330-2341.

11. Hsu YT, Youle RJ. Bax in murine thymus is a soluble monomeric protein that displays differential detergent-induced conformations. J Biol Chem 1998; 273: 10777-10783.

12. Desagher S, Osen-Sand A, Nichols A, Eskes R, Montessuit S, Lauper S et al. Bid-induced conformational change of $\mathrm{Bax}$ is responsible for mitochondrial cytochrome $c$ release during apoptosis. J Cell Biol 1999; 144: 891-901.

13. Zha H, Fisk HA, Yaffe MP, Mahajan N, Herman B, Reed JC. Structure-function comparisons of the proapoptotic protein Bax in yeast and mammalian cells. Mol Cell Biol 1996; 16: 6494-6508

14. Sattler M, Liang H, Nettesheim D, Meadows RP, Harlan JE, Eberstadt M et al. Structure of Bcl-xL-Bak peptide complex: recognition between regulators of apoptosis. Science 1997 275: 983-986.

15. Liu D, Yao H, Chen Y, Feng Y, Wang J. The N-terminal 26-residue fragment of human programmed cell death 5 protein can form a stable alpha-helix having unique electrostatic potential character. Biochem J 2005; 392 (Part 1): 47-54.

16. Liu X, Dai $S$, Zhu Y, Marrack $P$, Kappler JW. The structure of a Bcl-xL/Bim fragment complex: implications for Bim function. Immunity 2003; 19: 341-352.

17. Fan J, Zhang Q, Tochio H, Li M, Zhang M. Structural basis of diverse sequence-dependent target recognition by the $8 \mathrm{kDa}$ dynein light chain. $J$ Mol Biol 2001; 306: 97-108.

18. Suzuki M, Youle RJ, Tjandra N. Structure of Bax: coregulation of dimer formation and intracellular localization. Cell 2000; 103: 645-654.

19. Hsu YT, Wolter KG, Youle RJ. Cytosol-to-membrane redistribution of Bax and $\mathrm{Bcl}-\mathrm{X}(\mathrm{L})$ during apoptosis. Proc Natl Acad Sci USA 1997; 94: 3668-3672.

20. D'Alessio M, De Nicola M, Coppola S, Gualandi G, Pugliese L, Cerella C et al. Oxidative Bax dimerization promotes its translocation to mitochondria independently of apoptosis. FASEB J 2005; 19: 1504-1506.

21. Nguyen HP, Seto NO, MacKenzie CR, Brade L, Kosma P, Brade H et al. Germline antibody recognition of distinct carbohydrate epitopes. Nat Struct Biol 2003; 10: 1019-1025.
22. Stanfield R, Cabezas E, Satterthwait A, Stura E, Profy A, Wilson I. Dual conformations fo the HIV-1 gp120 V3 loop in complexes with different neutralizing fabs. Structure 1999; 7 : 131-142.

23. Cartron PF, Gallenne T, Bougras G, Gautier F, Manero F, Vusio P et al. The first alpha helix of Bax plays a necessary role in its ligand-induced activation by the $\mathrm{BH}$-only proteins Bid and PUMA. Mol Cell 2004; 16: 807-818.

24. Eskes R, Desagher S, Antonsson B, Martinou JC. Bid induces the oligomerization and insertion of Bax into the outer mitochondrial membrane. Mol Cell Biol 2000; 20: 929-935.

25. Cartron PF, Priault M, Oliver L, Meflah K, Manon S, Vallette FM. The N-terminal end of Bax contains a mitochondrial-targeting signal. J Biol Chem 2003; 278: 11633-11641.

26. Cartron PF, Arokium H, Oliver L, Meflah K, Manon S, Vallette FM. Distinct domains contro the addressing and the insertion of Bax into mitochondria. J Biol Chem 2005; 280: 1058710598

27. Makin GW, Corfe BM, Griffiths GJ, Thistlethwaite A, Hickman JA, Dive C. Damage-induced Bax N-terminal change, translocation to mitochondria and formation of Bax dimers/ complexes occur regardless of cell fate. EMBO J 2001; 20: 6306-6315

28. Valentijn AJ, Metcalfe AD, Kott J, Streuli CH, Gilmore AP. Spatial and temporal changes in Bax subcellular localization during anoikis. J Cell Biol 2003; 162: 599-612.

29. Yethon JA, Epand RF, Leber B, Epand RM, Andrews DW. Interaction with a membrane surface triggers a reversible conformational change in Bax normally associated with induction of apoptosis. J Biol Chem 2003; 278: 48935-48941.

30. Annis MG, Soucie EL, Dlugosz PJ, Cruz-Aguado JA, Penn LZ, Leber B et al. Bax forms multispanning monomers that oligomerize to permeabilize membranes during apoptosis. EMBO J 2005; 24: 2096-2103.

31. Nechushtan A, Smith CL, Lamensdorf I, Yoon SH, Youle RJ. Bax and Bak coalesce into novel mitochondria-associated clusters during apoptosis. J Cell Biol 2001; 153: 12651276

32. Capano M, Crompton M. Biphasic translocation of Bax to mitochondria. Biochem J 2002 367 (Part 1): 169-178

33. De Giorgi F, Lartigue L, Bauer MK, Schubert A, Grimm S, Hanson GT et al. The permeability transition pore signals apoptosis by directing Bax translocation and multimerization. FASEB J 2002; 16: 607-609.

34. Pflugrath JW. The finer things in X-ray diffraction data collection. Acta Crystallogr D Biol Crystallogr 1999; 55 (Part 10): 1718-1725.

35. CCP4\#\#The CCP4 suite: programs for protein crystallography. Acta Crystallogr D Bio Crystallogr 1994; 50: 760-763.

36. Navaraza J. AMoRe: an automated package for molecular replacement. Acta Crystallogr A Biol Crystallogr 1994; 50: 157-163.

37. Brunger AT, Adams PD, Clore GM, DeLano WL, Gros P, Grosse-Kunstleve RW et al. Crystallography \& NMR system: A new software suite for macromolecular structure determination. Acta Crystallogr D Biol Crystallogr 1998; 54 (Part 5): 905-921.

38. Jones TA, Zou JY, Cowan SW, Kjeldgaard M. Improved methods for building protein models in electron density maps and the location of errors in these models. Acta Crystallog A 1991; 47 (Part 2): 110-119. 